\title{
ENTRE CINEMA E FOTOGRAFIA
}

\section{André Parente}

\section{Resumo}

Há quase uma década temos pesquisado o cinema de artista no Brasil por meio da análise de seus autores, filmes, vídeos e instalações. Ao longo do tempo, notamos que uma das principais tendências do cinema experimental produzido pelos artistas brasileiros está relacionada com o processo de hibridização entre o cinema e a fotografia, um tipo de situação híbrida que rompe com as convenções das formas hegemônicas do cinema e da fotografia, da imagem em movimento e da imagem fixa. Neste sentido, decidimos desenvolver uma reflexão crítica que tem como objeto a relação entre cinema e fotografia no campo ampliado da arte contemporânea brasileira. Esta pesquisa se faz necessária por três razões: em primeiro lugar, a maioria dos teóricos e críticos da fotografia e do cinema rejeita estas experiências, visto que, para eles, elas escapam às convenções associadas a esses meios. Em segundo lugar, os críticos e teóricos da arte, em cujos circuitos esses trabalhos circulam mais frequentemente, no mais das vezes, não possuem o instrumental conceitual necessário para analisar esses fenômenos e, portanto, o fazem de forma muito superficial. Finalmente, os raros críticos capazes de analisar essa produção híbrida acabam por privilegiar obras estrangeiras consagradas (Andy Warhol, Hollis Frampton, Michael Snow, Cindy Sherman, Hiroshi Sugimoto, Douglas Gordon, David Claerbout, só para citar alguns dos mais conhecidos) que se inserem dentro da problemática - no máximo levam em conta a série "Cosmococas", de Hélio Oiticica e Neville d'Almeida, já que ela ganhou um status internacional -, deixando de lado, por preguiça ou insegurança, a produção nacional, que é muito extensa e potente.

\section{Palavras-chaves:}

Cinema; Fotografia; Arte Contemporânea; Arte e Novas Mídias

\section{Abstract}

For almost a decade we have researched film artist in Brazil through analysis of their authors, fil$m s$, videos and installations. Over time, we noticed that one of the main trends of the experimental film produced by Brazilian artists is related to the process of hybridization between cinema and photography, a kind of hybrid situation that breaks with the conventions of hegemonic forms of cinema and photography, the moving image and still image. In this sense, we decided to develop a critical reflection that focuses the relationship between film and photography in expanded field of contemporary Brazilian art. This research is necessary for three reasons: first, most theorists and critics of photography and film rejects these experiences because, for them, they escape the conventions associated with these means. Secondly, critics and art theorists, whose circuits in these works circulate more frequently, in most cases, lack the conceptual instruments necessary to analyze these phenomena and therefore do a very superficial way. Finally, critics can analyze this rare hybrid production ultimately privileging foreign works devoted (Andy Warhol, Hollis Frampton, Michael Snow, Cindy Sherman, Hiroshi Sugimoto, Douglas Gordon, David Claerbout, just to name a few of the best known) that fall within the problem - maximum take into account the "Cosmococas" series, Hélio Oiticica and Neville d'Almeida, since she gained an international status - leaving aside, for laziness or insecurity, domestic production, which is very extensive and powerful.

\section{Keywords:}

Cinema; Photography; Contemporary Art; New Media Art. 


\section{Introdução}

O que representa esse agenciamento da fotografia e do cinema, agenciamento que potencializa o cinema, livrando-o do fluxo narrativo, mas que, por outro lado, potencializa a fotografia, livrando -a disso que Barthes chamava "a realidade intratável"? É o que veremos neste texto.

Antes dos anos de 1970 havia uma dicotomia forte entre a fotografia e o cinema: de um lado, o movimento, o fluxo narrativo, o presente, o consentimento dessa ilusão do presente e de duplicação da vida; de outro, a imobilidade, o passado, a busca da alucinação e da duplicação da morte. Dois mundos à parte. Foi preciso que os artistas do pós-guerra investissem na fotografia e no cinema para dissolver-se esta clivagem.

Mas, desde o final dos anos de 1960, o cinema não só toma a fotografia como tema e material dos filmes (Andy Warhol, Paul Sharits, Hollis Frampton, Michael Snow, Antonio Manuel, Sonia Andrade) como também é tematizado por ela (Ana Vitória Mussi, Cindy Sherman, Sophie Calle, Hiroshi Sujimoto, Jeff Wall, James Coleman, Solon Ribeiro). Quando isso ocorre, o cinema se torna uma imagem que pensa (o que Bellour chama de "o espectador pensativo") e a fotografia encontra a cinematicidade do cinema ("efeito filme", na expressão de Dubois).

Não seria possível em um texto como este definir as relações tão complexas do cinema com a fotografia e as artes plásticas. Em todo caso, gostaria de chamar atenção para duas ou três questões, todas elas surgidas nos anos de 1970. A dicotomia entre a fotografia e o cinema (Roland Barthes), o conceito de acinema (Jean-François Lyotard), a parada na imagem produzida pelo vídeo (Serge Daney) e o conceito de efeito filme (Philippe Dubois). Cada um a seu modo, todos eles apontam para a questão da parada da imagem e da possibilidade de pensar as relações entre a fotografia e o cinema para além da representação: o terceiro sentido barthesiano, o acinema de Lyotard, a parada na imagem de Daney e o efeito filme de Dubois nada mais são do que um modo de dizer: o cinema e a fotografia se hibridizam em uma dimensão intermediária, entre-imagens, uma dimensão virtual propriamente irrepresentável.

Os próprios cineastas já haviam trazido à tona este problema. Por um lado Hollis Frampton nos mostra que o problema do cinema não é o conteúdo das imagens, mas as próprias imagens. 0 que importa é algo que está entre o fotograma e a imagem em movimento. O cinema é o que se passa entre a fotografia e o cinema, portanto, algo que é ao mesmo tempo a potência desta imagem e a sua autorreferência. Estas questões levaram Peter Kubelka a afirmar que "o cinema não é movimento, mas a projeção de imagens fixas".

$O$ que representa hoje o agenciamento cinema e fotografia? A possibilidade de criação de um olhar variável, que pode modular à sua guisa a passagem do móvel ao imóvel de forma a dissolver a dicotomia do móvel e do imóvel. É curioso notar que grande parte desse processo surge com o vídeo: o vídeo é da ordem do processual, da variável, da flutuação, da desmaterialização dos movimentos e dos corpos que mostra. Para completar a situação, o agenciamento fotografia e cinema produz uma complexificação do espaço-tempo da imagem numa série de hibridizações inauditas que mesclam a mobilidade e a imobilidade.

Em sua exposição "Movimentos improváveis" (2003), Philippe Dubois, crítico e curador, colocava já algumas questões quanto ao movimento da imagem: trata-se de um movimento da imagem ou na imagem? Uma imagem dita fixa pode apresentar movimento? Uma imagem dita em movimento pode apresentar imobilidade? E o que dizer das formas intermediárias entre o movimento e a imobilidade como, por exemplo, imagens "tremidas" ou "suspensas"? Como lidar com a desaceleração e congelamento da imagem nos filmes? É possível fazer um filme de imagens fixas? O movimento é sempre visível ou não? A partir de quando e até onde pode haver movimento? Quais são todos esses dispositivos de ilusão inverossímeis que nos fazem acreditar no movimento em que não há movimento?

No Brasil, além do audiovisual, vários artistas, entre os quais Sonia Andrade, Ana Vitória Mussi, Rosangela Rennó, Frederico Dalton, Solon Ribeiro, Katia Maciel, Dirceu Maués e eu mesmo, cada um a seu modo, aprofundaram esta relação entre cinema e fotografia. 


\section{Inverso e Multimeios}

Além de realizar, nos anos de 1970, uma série de instalações fotográficas, Sonia Andrade, como acabamos de ver, faz um vídeo no qual a imagem congelada tem um papel imenso na criação da imagem-cristal. Na série "Goe, and Catche a Falling Starre", como vimos, a imagem de vídeo, que está no presente, aparece congelada, como pura potencialidade, enquanto a imagem atual dos objetos está presa a um passado morto: a camisola ("Noturno"), a onda ("Périplo") e a estátua de Apolo ("Apolo").

Na série de fotografias "Situações negativas", a artista reuniu, em um único conjunto de seis instalações, as suas maiores problemáticas: as da imagem-objeto, as da imagem-corpo e as da imagem-cristal. Mas é na instalação "Inverso", apresentada na área experimental do MAM em 1976, que Sonia cria uma situação extraordinária: as fotografias (também de 18 por $24 \mathrm{~cm}$, como nas outras séries de situações negativas) são rastros de avião deixados no céu, que ocupam três faces de uma sala retangular. Do lado da face vazia, é colocado um projetor que projeta a luz branca sobre um prisma, gerando dois belíssimos arco-íris dessa imagem-cristal que virou a marca de Sonia Andrade.

Para concluir com as contribuições de Sonia Andrade, uma das pioneiras da arte e tecnologia no Brasil, para mostrar que o trabalho dela, embora seja muito atual do ponto de vista do pensamento em rede, foi feito utilizando-se de meios hoje considerados rudimentares e ultrapassados, no caso o postal e o vídeo, principais meios de inscrição e circulação do trabalho: ou seja, a imagem fixa e em movimento. "Multimeios" se insere dentro do contexto do que Walter Zanini organizou, na Bienal de 1977, em torno da Arte Postal, que depois inclusive foi publicada como um catálogo à parte da Bienal.

O trabalho é dividido em quatro etapas. Seria bom seguir pela ordem das partes para não nos perdermos no emaranhado dessa rede complexa do ponto de vista do processo. Na verdade, o que vemos no espaço expositivo é apenas o resultado do que circulou na rede, que eu chamaria, com Latour, de rede de mobilização. $O$ que a gente tem como espaço é uma espécie de canteiro de obras que mostra como o trabalho foi feito e o resultado do processo. Sendo que o que importa não é o que é visto, mas o processo de circulação, bem como a rede de atores articulados à qual remetem os objetos que são vistos.

Na primeira etapa, "Caminhos", é traçado, em um velho mapa viário do estado de São Paulo, o caminho que vai do Rio de Janeiro, onde Sonia vivia e trabalhava, ao local da exposição da Bienal. $\mathrm{Na}$ segunda, "Os habitantes", antigos postais (representando pessoas em indumentárias do início do século $X X$ ) são enviados aos membros da organização da Bienal, solicitando-Ihes que os encaminhem ao estande da obra. Na terceira, "O espetáculo", um vídeo reproduz a imagem de antigos postais de cidades e de paisagens enviados aos habitantes de localidades neles representadas, aos quais foi solicitado que enviassem para a exposição um postal do tempo presente. A quarta etapa, "A obra", é constituída por um painel no qual é exposta a correspondência entre a artista e a instituição (Bienal), contendo o projeto de sua obra, bem como as respostas aos diversos postais enviados.

Na verdade, a estratégia de Sonia é bastante contemporânea. Ela expõe não uma imagem pronta e acabada, mas uma imagem em rede, fruto da rede de relações que se estabelece entre um determinado fenômeno (cidades e paisagens) e a rede em que este fenômeno é produzido como realidade. Esse trabalho mostra claramente que as imagens, para se fazerem informação, espetáculo, obra, enfim, "realidade", supõem uma rede de atores diversos (a realidade física representada, a fotografia, o meio empregado para fazê-la circular, a instituição que vende e/ou expõe o produto, os consumidores do produto etc.) que dão sustentação e significado ao que nela circula. Na verdade, a obra de Sonia não mostra nada, ela demonstra a estratégia mesma da arte contemporânea, o fato de que não há obra independente das redes em que circulam e são constantemente produzidas e reafirmadas por todos aqueles que a elas aderem como atores e consumidores. Em vez de produzir uma obra a mais, Sonia optou por fazer do trabalho o processo mesmo de sua constituição em rede.

E finalmente a obra, a instalação, contém todos esses elementos multimeios: mapas, fotos, diagramas, postais, vídeo, cartas etc. $\mathrm{E}$ o que é interessante, no fundo, é que esse trabalho funciona 
como uma espécie de fotografia-rede, ou seja, ele é um trabalho que mostra toda a rede de atores de um determinado ponto de vista, não só a rede de atores, mas os processos, os suportes, os materiais, os bilhetes, enfim, tinha todas as correspondências, os catálogos telefônicos, os mapas, tudo. Continha um registro de tudo que foi feito, de todos os materiais usados, de todos os elementos e as redes, as relações que foram sendo tecidas etc.

Na verdade, falar desta obra hoje tem um aspecto político, visto que ela se constitui de elementos heterogêneos, humanos e não humanos, discursivos e perceptivos, suportes variados de inscrição da informação e tecnologias, que operam e transformam essas informações. Esses elementos formam uma grande rede que nada mais é do que uma rede de mobilização resultante do trabalho: suportes, atores, percursos e processos mobilizados. Essa ideia de rede de mobilização descrita pelo filósofo Bruno Latour fica aqui claramente evidenciada, esta afirmação de que a ciência, a religião e a arte são, primordialmente, tipos específicos de rede de mobilização. Para ele, não existe nem natureza (ciência), nem deus (religião), nem arte que não circule nestas redes de transformação. É apenas a rede que pode dar sentido ao que seja ou não verdade e relevante nestes campos.

Este trabalho de Sonia deixa muito claro isso: o fato de que o trabalho é justamente todo o processo de rede que se fez naquele momento. Se ela estivesse hoje em dia trabalhando, usando esse tipo de processo, ela certamente estaria usando outros meios que as pessoas chamariam de arte telemática ou alguma coisa do gênero. Na época ela recorreu ao postal, a arte postal sendo uma espécie de precursora da arte telemática.

\section{Bang}

Ana Vitória Mussi - que, juntamente com Sonia Andrade, integrava o grupo de pioneiros da videoarte - é simplesmente um dos artistas que mais contribuíram para transformar a fotografia em algo mais do que uma superfície dimensional ampliada em papel e exposta na moldura ou parede. Na verdade, a produção e a pesquisa de Ana Vitória, desde os anos de 1970, criaram uma fotografia em seu campo ampliado. Em primeiro lugar, as imagens fotográficas da artista podem se originar do jornal, da televisão ou do cinema, no confronto entre estes dispositivos e a câmera fotográfica. Em segundo lugar, a imagem resultante pode passar por um processo de transformação, por meio do qual a artista desenha, pinta ou grava sobre a imagem, ou a partir da imagem. Finalmente, a imagem/foto pode ser exposta usando-se de meios dos mais variados: diapositivos (às vezes sobrepostos), caixas de luz, projeção da foto ou sobre a foto, a instalação (com ou sem projeção), impressão em materiais diversos (geralmente em materiais transparentes) etc.

Vários críticos, dentre os quais Paulo Herkenhoff, Fernando Cocchiarale, Glória Ferreira e Marisa Flórido têm acompanhado de forma quase sistemática a obra de Ana Vitória. Entre algumas características de seu trabalho, destaco a mistura de procedimentos de fabricação da imagem, a tensão entre a transparência e a opacidade, 0 alto contraste das imagens gerando formas "construtivistas" ou "expressionistas", a incerteza quanto aos movimentos sutis criados na imagem por meio de variações de luz, a criação de fotos-objetos e instalações nas quais os movimentos são criados em parte pelo deslocamento no espaço do espectador.

Entre os diversos trabalhos de Ana Vitória, o que mais suscita a nossa atenção neste capítulo é a foto-instalação "Bang", realizada em 2012 (Oi Futuro, Rio de Janeiro), com curadoria de Marisa Flórido. Na instalação, são utilizados quatro projetores nas três paredes da sala à exceção da parede de entrada, em que ficam os espectadores. Estas projeções são acompanhadas da música "Bang Bang - My Baby Shot Me Down" (Sonny Bono), na versão de 1966 de Nancy Sinatra, recentemente popularizada pelo filme Kill Bill (Tarantino, 2003). A instalação dura aproximadamente o tempo da música, algo em torno de 4 minutos. ${ }^{1}$

"Bang" é um slide-show realizado com imagens de arquivo (são 237 fotografias feitas ao longo de três anos): filmes hollywoodianos de guerra ("Pearl Harbor", “Tora! Tora! Tora!", “O mais longo dos dias", "O choque final", "Raposa do deserto", entre outros), imagens de documentários de guerra ("Coleção Segunda Guerra Mundial") e guerrilha urbana (imagens da ocupação do Complexo do Alemão cedidas pela Globo), além de imagens dos dois documentários clássicos de Leni Riefenstahl ("Olympia" e "O triunfo da vontade"). Entretanto, 
as imagens ganham certa uniformidade, uma vez que são fotografadas em preto e branco, da tela da televisão, procedimento já utilizado por Ana Vitória em outros projetos como na série "Box na TV" (1975). Esta aparente uniformidade, acentuada pela montagem e pelo tema comum da guerra, nos induz a criar nexos narrativos entre as imagens, quando na verdade não há propriamente uma narrativa, mas um conjunto de imagens que, pela temática e montagem, cria a sensação de narratividade.

A instalação se divide em pelo menos quatro momentos distintos. Adolfo Montejo Navas descreve muito bem a orquestração rítmica de "Bang":

Nas coordenadas espaço-temporais de "Bang" podem ser vislumbradas diferentes combinações de imagens e uma pauta medida, rigorosa. Assim, primeiro existe um ritmo compassado, regular (um andante com inúmeras imagens indagando sobre a função do olhar), depois uma passagem levemente mais rápida (onde o olhar também se orienta e se tensa para o céu), até a ponte da legenda enigmática de "Nem uma gaivota..." que funciona como pausa, verdadeira divisão de águas da obra (pois até este momento é muda a apresentação e agora começará a se escutar a canção de Nancy Sinatra); logo virá uma nova fase regular de imagens mas com certa vivacidade (atletas saltando junto a aviões caindo), para chegar à fase que representa o ponto álgido, o molto vivace das imagens disparadas ao mesmo tempo (com a maior associação de cenas violentas), para fechar com uma nova e normal pulsação de imagens até o final, outro andante. (NAVAS, 2013, p. 78)

"Bang" cria uma pedagogia da violência. Esta pedagogia tem duas faces: por um lado, está claro, como diz Marisa Flórido, "que o que importa não é fotografar a guerra, mas seus modos de visibilidade e espetacularização: o que relaciona a imagem à violência e a violência à imagem, o que torna indistinto o homo videns do homo belicus." (FLORIDO, 2013, p. 8)

Em "Bang", há uma dramaturgia em que os corpos fotografados e os nossos próprios entram neste fogo cruzado que implica em um embate entre as imagens que trazemos em nós e estas que a artista nos propõe. O cinema de arquivo frequentemente se depara com este paradoxo do tempo: ou o tempo é invenção, ou ele não é nada. Portanto, devemos ser capazes não apenas de recriar e remontar as imagens que encontramos, mas de trazê-las de volta do passado mostrando que elas se prolongam no presente. Em "Bang", esta mulher que me olha, esta arma que me atira, esta música que me faz cair por terra. Este filme de muitas asas me faz flutuar como um anjo sobre Berlim, sem poder esquecer que ainda somos filhos desta guerra. Como diz Katia Maciel:
A instalação "Bang", de Ana Vitória Mussi, nos acorda com a delicadeza das imagens que flutuam no presente de um passado que não passa nun- $c a$, porque as imagens são mais que arquivos: são percepções incrustadas em nossos corpos, como a guerra e o cinema. E o tempo é bergsoniano por- que aqui o passado é contemporâneo do presente que ele foi. Nos termos colocados por Gilles Deleu- ze, a duração é uma memória, porque ela prolonga o passado no presente. (MACIEL, 2013, p. 23)

Todos os procedimentos rítmicos, narrativos, sonoros de "Bang" criam uma alternância, no limite do insuportável, entre as misérias e as belezas que esta máquina de guerra produz. É disto que este trabalho nos fala. Não se trata apenas de um devir cinema da fotografia, ou de um devir imagem-tempo da imagem, mas de uma obra que me convoca a ver isto que não podemos ver porque já se encontra em nós como um passado, modificável ou não. Em "A invenção de Morel"2, de Bioy Casares, a máquina do tempo criada por Morel nos faz vislumbrar a possibilidade de um tempo em que o passado pode ser modificável (o passado é o que é repetido pelo dispositivo) ao preço da eliminação do futuro. Em "Bang", a modificação do passado, ao contrario, é a única forma de afirmamos o futuro como algo realmente ainda por vir.

No entanto, há em "Bang" um desejo de desejo (um desejo em suspensão) difícil de explicar, senão fazendo um paralelo com "Asas do desejo" (Wim Wenders, 1987). Um filme que promove o encontro aéreo, impossível, entre o Anjo e a Trapezista. Ele sem presente e ela sem futuro. Em uma arte que é cada vez mais uma imagem sem presente, ou melhor, de um presente que se tornou um curto-circuito entre um passado e um futuro anteriores, "Bang" nos traz de volta um tempo não reconciliado, o da violência exorcizada pela imagem que a criou, numa visão que não deixa de ser "exótica", pois entramos neste mundo estranho como se nunca tivéssemos saído dele.

\section{O golpe do corte}

Solon Ribeiro, artista cearense com formação na Escola Superior de Arte Decorativa de Paris, tem 
seu trabalho voltado para a imagem fotográfica. Como é o caso de muitos artistas contemporâneos, seu trabalho atenta para a problematização do fenômeno contemporâneo da saturação de imagens. Para Sólon, a imagem é um mistério e precisamos ressuscitar seus aspectos mágicos e metafísicos.

Nos anos de 1990, Solon herda de seu pai uma imensa coleção de mais de 30 mil fotogramas de filmes, iniciada nos anos 1950 por seu avô Ubaldo Uberaba Sólon, dono de sala de cinema no interior do Ceará. Os fotogramas, em geral mostrando os principais atores dos filmes, eram cuidadosamente guardados em álbuns feitos para este fim, contendo o nome e o ano do filme, bem como o nome dos atores. Uma parte da coleção, que está fora dos álbuns, foi guardada de forma imprecisa, de modo que fica difícil saber de que filmes as imagens foram extraídas.

"O golpe do corte", termo utilizado por Solon para a série de vídeos e instalações feitos com os fotogramas desta coleção, contém dois momentos essenciais: o golpe do corte que constitui a extração dos fotogramas dos filmes e o posterior corte operado por Solon pela ação de montagem e encenação das imagens dos fotogramas.

Em um dos trabalhos, Solon utiliza fotogramas com legendas e cria um diálogo imaginário entre os personagens. Em outro, ele projeta os fotogramas de cima, enquanto maneja uns almofadões sobre os quais se deita, de forma que eles possam refletir melhor as imagens dos fotogramas. Curiosamente o artista parece um ator do cinema expressionista, um tanto incomodado pelas imagens que sobre ele são projetadas, como se elas fossem clichês que, porventura, pudessem roubar-Ihe a alma.

Vemos nos trabalhos de Solon uma radicalização do espírito contida nas "Cosmococas", que é a de, partindo de imagens clichês, criar uma situação de ruptura com o NUMB-CINEMA, de modo a criar um cinema participativo, no qual o espectador tem seu corpo liberado pelo CORPO-ROCK. Ou seja, a partir dos momentos-clichês dos fotogramas, extrair uma performance ambiente que envolve tanto os espectadores como o próprio artista. É bom lembrar que, em um de seus primeiros trabalhos, Solon projetava as imagens sobre os corpos dos espectadores, a exemplo do "Corpocinema" de Jeffrey Shaw.
Em seus últimos trabalhos, Solon projetava os frames sobre seu próprio corpo. Em um dos vídeos, Solon aparece em um matadouro, em meio aos restos dos bois mortos. As imagens dos fotogramas, cheias de glamour, são completamente violentadas por meio de gestos do artista que interage com a carne, com o sangue, com as tripas e com as imagens: ora ele parece o Bandido da Luz Vermelha, ora, Glauber Rocha em transe. $\mathrm{Na}$ verdade, os trabalhos quasi-cinema de Solon estão estreitamente relacionados, por um lado, à forma como Oiticica e Neville se apropriam das imagens "pops" de Marilyn Monroe, Jimi Hendrix e Mick Jagger para renová-las. Em outros momentos, o trabalho de Solon ultrapassa o sentido da apropriação por meio da parada na imagem para se tornar uma espécie de arquivo vivo com uma dimensão performática.

O que nos chama atenção no trabalho de Solon não é apenas o fato de ele possuir esta dimensão fractal, intermediária, que nos coloca sempre entre as imagens, entre a fotografia e o cinema, entre o cinema e a instalação, entre o espectador e o autor. $O$ que nos chama a atenção é, sobretudo, a forma como o trabalho de Solon é um convite ao espectador para que ele crie a sua própria fabulação, a partir dos golpes e dos cortes operados pelo artista. Afinal, se Solon não gosta de se definir como um artista, é porque o artista, como diria Godard, se fixa num substantivo de majestade que destrói qualquer possibilidade de fabulação. O golpe de Solon consiste em um convite para que o espectador participe da mobilidade da obra, um convite, a la Herman Melville, para que o espectador se perca na imagem - assim como ele também, Solon, um dia se perdeu - como uma forma de se renovar, de se recriar, de se reencontrar no outro.

Por um lado, os fotogramas utilizados por Solon são como restos das imagens criadas pela máquina de Morel, imagens despotencializadas, frutos de um mal de arquivo que seu avô acolheu. Como animá-las? Como trazê-las de volta à vida? Ao contrário do personagem do livro de Bioy Casares, ele prefere entrar na imagem, mesmo conhecendo o risco que corre.

A imagem é o canto das sereias. Não se pode negar que Ulisses o tenha ouvido. Entretanto, diz Maurice Blanchot, a astúcia de Ulisses consiste em manter o intervalo entre o real e o imaginário 
que o canto o convida a percorrer. Em outras palavras, ele sabe quem ele é e quem são as sereias. A questão, porém, é que o homem verídico é muito prudente, e faz um grande esforço para desacreditar as sereias, acusando-as de mentirosas e fictícias. No universo de Melville, Achab viu aquilo que Ulisses escutou. Enquanto Ulisses manteve sua prudência, Achab se perdeu na imagem. Isto mostra que Ulisses recusou-se à metamorfose na qual o outro penetrou e desapareceu. Em "O golpe do corte", Solon se apresenta como o personagem de Achab: ele quer se perder nas imagens, confundir-se com elas, numa tentativa de afundar neste espaço sem mundo.

O golpe de cinema de Solon se insere dentro da tradição do cinema de invenção no Brasil, a de um cinema cujo personagem principal apresenta o que poderíamos chamar, de maneira provisória, de uma certa idiotia do real como força espiritual. São, no mais das vezes, mentecaptos, zumbis, macabéas, visionários e autômatos espirituais que habitam cada um de nós, na medida em que são como que a pré-história de nossas consciências ("O super-outro"), de nossos pensamentos e impossibilidades de pensamento ("A hora da estrela" e "Mar de rosas"), de nossas sexualidades ("Copacabana mon amour", "O homem do Pau-Brasil" e "Piranhas no asfalto"), de nossas línguas ("Tabu" e "Sermões"), de nosso subdesenvolvimento ("O Bandido da Luz Vermelha" e "Vidas secas"), de nossos corpos maltratados e famintos ("A opção ou as rosas da estrada" e "Jardim de espuma"), salvos pela carnavalização e pela antropofagia ("A lira do delírio"), de nossa inocência ("Inocência" e "Nosferatu do Brasil"), de nossa loucura ("Loucura e cultura", "A idade da Terra", "Imagens do inconsciente" e "Matou a família e foi ao cinema"), de nossa idiotia total ("Bang Bang", "Sem essa aranha"), que é a única forma de superação do intole-rável que habita a nossa socieda $\rightarrow$ de. Pois só a idiotia pode nos salvar da estupidez dos bárba $\rightarrow$ ros arrogantes que fazem a medio $\rightarrow$ cridade triunfar em tudo. Como diria Dostoievski, "Ele é idiota, mas é um príncipe". Tais personagens tiram suas determinações espiri $\rightarrow$ tuais de suas fraquezas, de um desejo desinteressado de afirmação da vida, de um desejo capaz de reunir a Terra ao Inconsciente. Com eles, é toda uma imagem-pensamento que se nos oferece como resistência às imagens-clichê e verdades preestabelecidas, veiculadas pelo poder.
Katia Maciel fez uma série de instalações de uma grande beleza, que misturam fotografia e cinema, mas, sobretudo, a paisagem, a árvore e a floresta em um arvorar que poderia ser considerado uma espécie de devaneio daquilo que Gaston Bachelard chama de a "árvore aérea".

Em "Inútil paisagem" (2007), Katia Maciel fotografa os prédios da praia de Ipanema, de frente. Depois, as imagens fotográficas são colocadas uma ao lado da outra, em uma única imagem. A edição apenas cria um movimento panorâmico muito suave e sutil para a direita que faz a imagem deslizar muito lentamente. Vemos uma depois da outra as entradas e jardins dos prédios gradeados de ponta a ponta - justamente no bairro em que a Bossa Nova foi inventada e onde provavelmente a música homônima de Tom Jobim teria sido feita trinta anos depois. Ao fim do movimento, a "câmera virtual" para e faz o movimento contrário para a esquerda. O que vemos é que as grades foram retiradas, criando a ilusão de que não há mais grade e gerando uma aparente sensação, ainda que virtual, de liberdade.

Se observarmos com atenção a imagem, vemos que a autora não se importou com os traços deixados pelo trabalho de extração das grades - que por sinal nos fazem lembrar as pinturas quase hiperrealistas de David Hockney -, que deixam seus rastros na carne da realidade, ainda que de uma realidade virtual, pois a ausência de paralaxe marca a sensação de uma falta de movimentos na relação entre os objetos verticalizados em profundidade. A sutileza do trabalho de Katia consiste em chamar nossa atenção para o contraste entre a beleza da paisagem da cidade do Rio de Janeiro e os problemas sociais que a deformam, por uma espécie de falta de sensibilidade. Se todos ouvissem "Inútil paisagem", quem poderia ter a ideia de gradear a nossa paisagem? Neste trabalho, a criação de uma fotografia em movimento é a condição de possibilidade para a colocação de uma pergunta: grade para quê, se a violência está na separação, na relação cindida entre o dentro e o fora? Desta forma, de um sintoma da violência, a grade se transmuta em uma de suas causas, ainda que virtuais. A ausência da paralaxe curiosamente só aumenta o contraste entre o nosso devaneio de liberdade criado pela verticalidade das árvores e a ausência de imaginação dos homens de negócio que hoje habitam esses prédios da orla. 
"Árvore" (2010) é um dos vídeos mais singelos e potentes de Katia. Uma árvore frondosa do Jardim Botânico é filmada em primeiro plano. A artista usou alguns frames da filmagem para criar a imagem de uma árvore que respira, em um movimento sutil de sístole/diástole. Curioso é perceber o movimento de respiração e pulsação de uma árvore. Como este movimento fosse capaz de despertar em nós os devaneios da imaginação da árvore aérea que existe em toda árvore. A árvore deixa de ser este "filtro" que transforma, por fotossíntese, o gás carbônico em oxigênio, transformando este ser estático por excelência em um ser capaz de despertar em nós os maiores devaneios das coisas voantes e frementes, talvez mais do que os pássaros (cf. BACHELARD, 2011).

"Arvorar" (2012) é uma instalação interativa na qual, por meio do sopro, os visitantes podem criar movimento na imagem de uma grande floresta, até então estática. Ao fazê-lo, sentimos toda a força criativa que os movimentos vegetais despertam em nossa imaginação. Ao experimentar "Arvorar" pela primeira vez fui tomado por um frêmito de quase alucinação - "arvorar" era um termo que nos anos 1970 era muito utilizado para estados alterados da consciência - que me fez lembrar um texto de Rainer Maria Rilke. $O$ texto discorre sobre a situação vivida por um leitor que passeava no bosque procurando um lugar para ler. De repente, ele se encosta a uma árvore e começa sua leitura. Mas eis que ele sente emanar das vibrações da árvore algo que lhe toca profundamente, como se seu corpo fosse tratado pela primeira vez como uma alma. Esta sensação cresce no homem a ponto de ele interromper a leitura para meditar sobre o que se passa. Depois de pensar sobre o encantamento que a troca com a arvorezinha Ihe proporcionou, ele conclui: eu fui conduzido ao outro lado da natureza. Esta constatação, vinda de Rilke, nos parece perfeita para exprimir a sensação causada em nós pela paisagem, pela árvore e pelo arvorar de Katia Maciel.

\section{Estereoscopia}

Ao longo do desenvolvimento do Visorama, um pesquisador do IMPA, Sergio Machado Pinheiro, desenvolveu um sistema de visualização de multirresolução. Isto nos permitia visualizar uma imagem grande demais (ela podia ter 3 GB ou 30 GB e a sua visualização não mudaria), como fazer sobre ela um zoom sem pixelizá-la. Quando vi este sistema, tive a ideia de fazer um trabalho em que a minha imagem fosse formada por milhares de imagens da minha mulher, Katia Maciel, ela também artista, bem como a imagem dela, em retorno, fosse formada por milhares de imagens minhas.

Instalação interativa baseada em duas imagens de um casal que se olha, em campo/contracampo. Um zoom infinito que envolve a imagem de duas pessoas fotografadas em campo/contracampo (dispositivo principal da representação audiovisual) reproduzindo, conceitualmente, a estrutura de uma imagem fractal (a parte contém o todo).

O trabalho coloca inúmeros problemas conceituais: a importância do "loop" na arte digital; a questão de uma imagem mosaico fotorrealista que obedece aos princípios da imagem fractal, em que as partes se confundem com o todo; a questão da disjunção da imagem e do som; a questão, muito atual, relativa à temporalidade nas imagens fotográficas e, finalmente, a questão de uma interatividade sonora autônoma.

As imagens-mosaicos têm a ver com a estética do fragmento, a saber, com a implosão da obra como centro e totalidade. Como disse Roland Barthes, "a incoerência é preferível à ordem que deforma". Entretanto, a poética do fragmento possui características, formais e de conteúdo, próprias. Formais: exprimir o caos sem reduzi-lo. Mostrar que um rosto ou uma paisagem aparentemente caótica são formados de muitas paisagens singulares que nos permitem realizar deslocamentos interessantes. De conteúdo: afastar o "monstro" da totalidade com a ideia de que uma imagem sempre "esconde" outra imagem ou remete a outra imagem. Trata-se de um convite para o espectador explorar a imagem como uma paisagem de paisagens, uma vez que uma paisagem remete a outras paisagens, ao infinito: "a desorientação seria a condição da paisagem" (Jean-François Lyotard).

O segundo aspecto está ligado à poética fractal. O fractal se apresenta como uma dimensão intermediária capaz de nos fazer transitar entre o contínuo e o descontínuo, a ordem e a desordem, o local e o não local, a parte e o todo, o campo e o contracampo. A dimensão fractal, intermediária, da instalação, é múltipla. Em primeiro lugar, há uma indiscernibilidade da instalação quanto à 
técnica. Não "sabemos" se é fotografia, cinema ou infografia. Por outro lado, quanto à imagem dos personagens, estamos sempre em uma dimensão intermediária, entre um e outro.

Por fim, quanto à relação entre o som e a imagem, há outro paradoxo, pois o diálogo fala de uma interioridade especular - "quero ver o que você está vendo de mim" - que é desmentida pela imagem, que é pura exterioridade, como na banda de Moebius. O diálogo, embora em primeira pessoa, é um discurso indireto livre, em que eu é outro. Vertigem que multiplica o que se ouve no que se diz, sempre o mesmo que continua o outro, que sou eu, que é você. "Eu quero ver o que você está vendo de mim dentro de você". Eco, fundo, tudo em mim é você. Em uma imagem vemos todas as outras. Mosaico que soma eus e você e vice-versa: "Eu quero ver o que você está vendo de mim do que eu estou vendo de você dentro de mim". Mantra do universo digital em que a repetição é o ritmo do que se vê. No jardim das delícias digitais, eu é você e você sou eu, compartilhando uma profundidade virtual infinita, porém a única que interessa, pois não é determinada tecnicamente, mas esteticamente.

\section{Belvedere}

Em 2010, realizei uma instalação na exposição "Tempo-Matéria" no Museu de Arte Contemporânea de Niteroi. ${ }^{3}$

${ }^{4}$ Trata-se de uma instalação site specific intitulada "Belvedere", composta de três partes. A primeira parte se constitui de um vídeo projetado em grande dimensão na parede do salão hexagonal do museu (11 metros de largura por 4 de altura). A imagem do vídeo mostra a paisagem que é vista da varanda, de um ponto de vista que se situa atrás da parede onde o vídeo é projetado, produzindo a ilusão de que o espectador está vendo através da parede. 0 vídeo mostra as mudanças da luz na paisagem ao longo do dia, da aurora ao anoitecer. Toda imagem fotomecânica, seja ela analógica ou digital, coloca o problema da relação com o referente. Ironicamente, o que separa essa imagem de seu referente é apenas a parede onde ela é projetada.

A segunda parte é composta por uma série de doze fotografias de 2007 do Belvedere situado na estrada Rio-Petrópolis, hoje em ruínas, cuja forma arquitetônica se assemelha à do MAC. Fixadas no outro lado da parede em que projeto a primeira imagem descrita acima, a visão do belvedere leva o público a questionar a relação arquitetural, funcional e artística entre as duas construções criadas para que a paisagem ao redor seja admirada.

A terceira parte é composta de um vídeo exibido em uma telinha de 7 polegadas fixada na parede ao lado das fotografias. Nesse vídeo, são mostradas imagens do Belvedere durante os anos de 1950 e de 1960, quando então se assemelhava um prédio futurista, no estilo dos prédios da série "Jetsons". Essas imagens são acompanhadas da música "Chega de saudade" (1958), clássico da bossa nova contemporâneo da construção do belvedere, em uma interpretação muito engraçada do grupo português "Os Desafinados", que a entoa usando apenas vozes e um forte sotaque lusitano carregado de melancolia. Música que propõe um deslocamento na maneira como vemos o que foi novo como algo que ainda persiste. Aqui o "chega de saudade" se apresenta como uma fórmula: chega de modernismo! Esse chega de modernismo é, por assim dizer, o lado irônico do trabalho como um todo.

\section{Segundo Fernando Gerheim,}

As paredes no interior do disco envidraçado de Niemeyer, que privilegia a paisagem da baía de Guanabara, formam um hexágono com intervalos entre os lados, e os trabalhos dos cinco artistas estão dispostos cada um nos dois lados de uma das paredes, com a sexta face aberta para o público entrar. Em "Belvedere" (2007-2010), de André Parente, a imagem da paisagem da Baía de Guanabara é projetada, em grandes dimensões, na parede à frente da paisagem real. A imagem panorâmica dessa vista foi gravada em outro dia e outra hora. As duas paisagens, uma real e outra um tromp-l'oeil digital, abrem uma fresta no tempo. Do outro lado da parede, vemos doze fotos do Belvedere da estrada Rio-Petrópolis, de arquitetura similar à do MAC, em seu estado atual, melancolicamente abandonado; e um vídeo baixado do YouTube com o mesmo mirante na década de 1960, em seu auge. No áudio, “Chega de saudade" na interpretação nostálgica de um grupo português. Somos deslocados de "dentro" para "fora", e de "fora" para "dentro", de modo que jamais a imagem confirma o lugar de onde a observamos. Ela volta o observador para o próprio espaço, o próprio museu modernista, suas projeções de futuro e passado. A imagem especular torna-se reflexiva. O trabalho site specific, que utiliza o dispositivo (a projeção) e o arquivo (o YouTube) faz uma crítica do museu e do modernismo através dos deslocamentos espaço-temporais que produz. (GERHEIM, 2010, p. 232-233) 
Para Rogério Luz, uma das principais características dos trabalhos desta exposição, e que coincide completamente com a dinâmica de "Belvedere",

É o movimento do tempo desencadeado a partir de um sítio. 0 sítio faz-se aí passagem, deslocamento, re-visão e imbricação de momentos, intervalo de trocas entre o interior e o exterior. Diferentemente da estética do modernismo, a arte volta-se sem cessar para o interior e para o exterior. Essa é, digamos, a mola mestra da exposição e também o elemento desestabilizador da experiência. ${ }^{5}$

\section{O Real no Virtual}

As instalações panorâmicas em geral, e o Visorama em particular, possuem virtualidades ainda inexploradas, que fazem convergir a arte contemporânea, o cinema e as interfaces computacionais, transformando radicalmente as dimensões tradicionais do cinema: sua arquitetura, sua tecnologia e sua narratividade. O Visorama é um sistema original e completo de realidade aumentada e multimídia baseado em ambientes virtuais fotográficos panorâmicos. 0 sistema comporta áudio e vídeo, mas a base é a fotografia. Trata-se de um sistema que simula um binóculo ou um telescópio, permitindo que o usuário possa usá-lo para interagir com uma paisagem real ou imaginária fotografada numa visão panorâmica de 360 graus e estereoscópica (3D)6.

No nível do hardware, o Visorama simula, por sua carenagem, um sistema ótico tradicional, no caso, um binóculo. 0 objetivo básico do aparelho é criar a ilusão, no observador, de que ele está olhando para o espaço circundante através da ocular do visor. A interação do observador com a realidade está relacionada com dois tipos básicos de deslocamentos: o zoom que permite ao espectador se aproximar das coisas vistas e um botão de evento que permite ao espectador fazer saltos no espaço e no tempo.

Já apresentei uma dezena de diferentes instalações - cada uma com um conteúdo diferente - com o Visorama. Nestas instalações, tratava-se, em primeiro lugar, de utilizar o Visorama para criar uma nova poética dos espaços urbanos. Gostaríamos de comentar uma das mais bem-sucedidas.

Quando o espectador olha pelo Visorama, é como se ele estivesse olhando através da ocular de um sistema ótico tradicional. O usuário poderá, por meio do Visorama, observar a paisagem ou o espaço urbano, como se ele lá se encontrasse, e se deslocar no espaço e no tempo por meio de movimentos panorâmicos e deslocamentos espaciais (realizados por meio de movimentos panorâmicos horizontais, verticais e zoom) e temporais. Ele será guiado, pelo seu interesse, em uma espécie de visita virtual ao espaço observado.

O Visorama foi inspirado no conceito deleuziano de imagem-virtual, conceito que nos permite entender de outra forma a realidade virtual. A imagem virtual, segundo Deleuze, é uma imagem que escapa às representações dominantes e às significações pressupostas do real. A realidade virtual, ao contrário, no mais das vezes, tem sido usada para produzir condicionamentos sensório-motores, como nos simuladores de voo.

"Berlin Cyber City", de Monika Fleishmann, é um exemplo de como a realidade virtual pode ser usada no sentido contrário ao do uso dominante, que é o de produzir condicionamentos sensório-motores. Ela parte da seguinte constatação: o Muro de Berlim acabou na realidade, mas ainda existe como imagem virtual na cabeça das pessoas. Para quebrar o muro na cabeça das pessoas, "Berlin Cyber City" faz coexistirem essas duas imagens de Berlim: a Berlim atual (sem muro) e a Berlim clichê (petrificada na cabeça das pessoas). A ideia de "Berlin Cyber City" existe como questão estratégica na arte de hoje: como extrair das imagens clichês, que nos invadem e nos impedem de ver o real enquanto novo, uma imagem que nos dê razão de acreditar no mundo em que vivemos. Se perdemos o mundo (não acreditamos mais nele), é porque nos deixamos aprisionar em uma trama de imagens clichês que nos impedem de ver o real, sempre novo. Portanto, cabe à arte nos dar um pouco de real ao desconstruir os clichês.

No caso do Visorama, este era o maior desafio: como utilizar a realidade virtual para fazer as pessoas verem o que elas já não podem ver, tão acostumadas que estão a olhar para a paisagem que as cerca. Embora o Visorama seja um sistema acabado do ponto de vista da sua tecnologia, trata-se de um "work in progress" do ponto de vista de suas diversas aplicações. Neste sentido, gostaríamos de comentar duas instalações realizadas.

Entre as dezenas de instalações desenvolvidas com o Visorama, "Figuras na Paisagem" (Oi Futu- 
ro, 2010) é uma das mais instigantes. O "Figuras na Paisagem" faz convergir a arte contemporânea, o cinema e as interfaces computacionais, transformando radicalmente as dimensões tradicionais do cinema: sua arquitetura (a sala), sua tecnologia (câmera e projetor) e sua linguagem (organização das relações espaço-temporais).

0 trabalho insere-se em um contexto de instalações contemporâneas de arte no qual o dispositivo torna-se uma estratégia de articulação entre a tecnologia, o espectador e um determinado regime de crenças, que tem por objetivo desencadear novas modalidades de experiência com as imagens.

Historicamente, as variações nos dispositivos audiovisuais implicaram em variações no regime espectatorial de cada época, por vezes acentuando a crença no realismo da mímese e da verossimiIhança, inserindo o observador na imagem, por outras promovendo o distanciamento, o estranhamento diante da representação. Hoje, a hibridização das imagens potencializada pelas novas tecnologias vem colocando em questão nossa tradicional visão da realidade e reinventando o papel do observador, mais uma vez, em decorrência das relações entre dispositivos e imagens.

Em um diálogo com a história do cinema, "Figuras na Paisagem" cria as condições para uma experiência que ao mesmo tempo retoma e reinventa outros dispositivos audiovisuais. Desde os primeiros panoramas fotográficos aos primeiros cinemas, passando pelo cinema clássico, pelos experimentalismos modernos e pela videoarte, o dispositivo e seu conteúdo (este muda a cada instalação, qual um filme em uma sala de cinema) dialogam com as tecnologias e com os regimes de arte e de observação de cada época.

Ao passo que retoma o funcionamento de um dispositivo conhecido historicamente, em um jogo de aproximação e distanciamento, "Figuras na Paisagem" escapa dos modelos pré-definidos. Os modos de aparição e desaparição das imagens, a fragilidade e a instabilidade da narrativa, sua apresentação como um fluxo e os diferentes papéis destinados aos observadores reconfiguram 0 lugar das imagens técnicas na contemporaneidade.

Logo de início, a primeira imagem a ser observa- da é a própria sala de exposição, silenciosa, vazia, imóvel. 0 espectador tem a impressão de estar a ver o espaço real no qual se encontra como se estivesse utilizando um binóculo de verdade.

O binóculo, aparelho que permite a visão estereoscópica das imagens fotográficas e videográficas presentes na obra, está suspenso no centro da sala, sugerindo a realidade para além dos limites oculares. A instalação torna-se um convite ao voyeurismo. Nesse estágio inicial, é preciso percorrer todo o panorama, de um lado a outro, para encontrar as passagens que levam às demais paisagens.

Pressionando um dos botões do aparelho, iniciamos um movimento de aproximação, um zoom na imagem, e adentramos a biblioteca ou a praia. Ao observador é dado, inicialmente, decidir entre a imagem de uma imponente biblioteca austera, circular, borgeana no sentido de sua aparente infinitude, e a cotidianidade da praia, popular, ensolarada, sempre acompanhada de micronarrativas. Diante das paisagens construídas, o observador é convocado a iniciar uma trajetória pela imagem que o leva a percorrer visualmente os panoramas através de escolhas que prescindem de seus próprios movimentos corporais. Ao performar uma dança "cega" com mãos e olhos firmes no binóculo, o observador constrói a sua própria narrativa audiovisual a partir do que escolhe ver e não ver, ouvir e não ouvir.

O dispositivo aqui se confunde com a obra instalativa, propondo uma "obra-dispositivo" que transforma o observador em criador a partir de uma relação estabelecida com a obra. É através desta ação performática que o observador vai criar suas narrativas únicas e conduzir as experiências individuais e coletivas. Enquanto desempenha sua ação "performático-criativa", o observador é também objeto de observação de outros visitantes, que se mantêm na sala de exposição e acompanham toda a narrativa por uma projeção na parede. Localizada à frente do binóculo, a projeção permite a todos, ao público e ao operador do binóculo, verem simultaneamente as mesmas imagens. A obra é então concebida de modo que a experiência não seja privilégio daquele que opera o aparelho, mas uma experiência compartilhada com o público, que reage às imagens e às escolhas do operador. 
A tela é um convite não apenas à observação, mas também à participação do público. A cada reação, de incentivo ou de recusa, o público acaba por interferir nas escolhas do observador, que não pode ignorar seus espectadores. A obra se constitui como uma rede de forças que produz experiências individuais e coletivas, em que os papéis dos observadores, do público e do artista se reinventam constantemente. As paisagens são construídas a partir da miscigenação de diversas imagens, fotográficas e videográficas, e das narrações de textos que remetem à situação do leitor e do observador. Ao longo do percurso escolhido, a obra oferece ao observador um diálogo entre as camadas de imagem e de som, entre a imagem e a literatura e entre o visível e o dizível.

Em uma das opções, o observador pode entrar na sala de leitura da biblioteca, a princípio vazia, e ouvir a narração do texto "A leitura silenciosa", escrito por Santo Agostinho no século $V$, em que o autor descreve a sua admiração diante do ato da leitura silenciosa do seu mestre, Santo Ambrósio, um maravilhoso espetáculo, símbolo da liberdade a ser alcançada pelo pensamento. Ao associar a biblioteca a um espaço interior mental, a palavra lida em silêncio aproxima-se do próprio pensamento. De modo paradoxal, a narração em voz alta do texto que disserta sobre o silêncio duplica a situação do observador, que vê o que não pode ser dito e ouve o que não pode ser visto.

No outro percurso, agora na praia, o observador pode, entre outras opções, deparar-se com a imagem videográfica de um homem nadando, enquanto ouve a narração que descreve a cena de um observador que acompanha visualmente um homem que nada no mar. Deixando-se levar pela narração, o observador se sente como sendo em parte responsável pelo que observa.

Em "Figuras na Paisagem", as narrativas são metáforas da condição mesma do observador. Há uma tensão constante entre o observador - colocado na situação de um voyeur olhando pelo buraco da fechadura - e o público, que assiste à criação de uma "narrativa singular" por parte do observador que manipula o aparelho.

\section{Notas}

1. Ao escrever sobre "Bang", utilizamos como referência quatro textos: o release da instalação escrito pela curadora Marisa Flórido no folder da exposicão; "Shot by Bang. Fotografia e imagem em movimento" (2013), de Greice Cohn; “Alvo e Fugor (Notas para Bang)", de Adolfo Montejo Navas e "Bang", de Katia Maciel. Estes dois últimos integram o catálogo "Ana Vitória Mussi", organizado por Marisa Flórido. Rio de Janeiro: Oi Futuro, 2013.

2. Um fugitivo, por motivos políticos, aporta em uma ilha onde a peste teria eliminado seus habitantes. Aos poucos ele descobre que a ilha não estava completamente desabitada. Entre seus habitantes, que parecem veranistas, chama-Ihe a atenção uma bela mulher que ele vê frequentemente a contemplar o entardecer à beira-mar. Um dia, ele percebe, não sem surpresa, que a muIher, Faustine, não reage à sua aproximação e que seus gestos se repetem de forma maquinal. Dia após dia o fugitivo observa Faustine e descobre que a máquina inventada por Morel possibilitava a reprodução dos últimos dias vividos por Morel na ilha ao lado de Faustine e de seus amigos. As imagens criadas geram no intruso a sensação de estar diante da própria realidade. A máquina funcionava com a energia gerada pela mudança da maré. Nos intervalos entre as marés, a máquina parava de funcionar, o que permitiu ao fugitivo descobrir o seu funcionamento. Além de ser uma mistura original de vários gêneros literários - a riqueza de ações dos romances de aventura, a força imaginativa da ficção científica, o rigor das narrativa policiais, a profundidade dos romances psicológicos e sentimentalidade das histórias de amor -, "A invenção de Morel" coloca uma série de questões metafísicas. Na verdade, ao contrário da "Alegoria da caverna", que nos leva a pensar a saída da imagem - o mundo é imagem, é aparência, e as aparências enganam, logo, é preciso saber olhar para o mundo com o olho do espírito e da razão -, "A invenção de Morel" nos convida a entrar na imagem. De fato, o narrador escolhe se transformar em uma imagem para fazer parte da realidade imagética do mundo criado por Morel, com a esperança de ser percebido por Faustine. Ele prefere se transformar em uma imagem e ser percebido por sua amada a continuar a viver em uma ilha deserta. 
3. A exposição, com curadoria de Luiz Claudio da Costa, apresentava também obras de Ricardo Basbaum, Lívia Flores, Leila Danzinger e Malu Fatorelli. Ficou combinado que cada artista teria uma parede para fazer seu trabalho, a superfície de 13 por 5 metros do lado de dentro do salão nobre (hexágono) e 13 por 3,5 metros do lado de fora, na "varanda".

4. Rogério Luz. Depoimento escrito enviado por pelo autor para ser lido na mesa redonda que houve no MAC em maio de 2010.

5. O hardware e o software do Visorama foram desenvolvidos entre 1997 e 2007 sob a minha coordenação em colaboração com o matemático Luiz Velho, fruto de uma parceria do Núcleo de Tecnologia da Imagem (N-Imagem) da UFRJ e do Laboratório Visgraf do IMPA, com o patrocínio dos seguintes organismos de apoio à pesquisa: $C N P q$, FINEP, FUJB e FAPERJ (Cf. www.eco.ufrj.br/figurasnapaisagem).

\section{Sobre o autor}

André Parente é artista e teórico do cinema e das novas mídias. Em 1987 obtém o doutorado na Universidade de Paris 8 sob a orientação de Gilles Deleuze. Em 1991 funda, juntamente com Rogério Luz, o Núcleo de Tecnologia da Imagem (N-Imagem) da Universidade Federal do Rio de Janeiro. Entre 1977 e 2007, realiza inúmeros vídeos, filmes e instalações nos quais predominam a dimensão experimental e conceitual. Seus trabalhos foram apresentados no Brasil e no exterior (Alemanha, França, Espanha, Suécia, Espanha, México, Canadá, Argentina, Colômbia, China, entre muitos outros). É autor de vários livros: Imagem-máquina. A era das tecnologias do virtual (1993), Sobre o cinema do simulacro (1998), O virtual e o hipertextual (1999), Narrativa e modernidade (2000), Tramas da rede (2004), Cinema et narrativité (L'Harmattan, 2005), Preparações e tarefas (2007), Cinema em trânsito (2012), Cinemáticos (2013), Cinema/Deleuze (2013), entre outros. Nos últimos anos obteve vários prêmios: Prêmio Transmídia do Itaú Cultural, Prêmio Petrobrás de Novas Mídias, Prêmio Sergio Motta de Arte e Tecnologia, Prêmio Petrobrás de Memória das Artes, Prêmio Oi Cultural 2010, Prêmio da Caixa Cultural Brasília, Prêmio Funarte de Artes Visuais, Prêmio Oi Cultural 2014, Premio XIV Marc Ferrez 2014. 